\title{
A música “O mundo é um moinho” como estratégia pedagógica para o ensino do tema transversal orientação sexual na escola... proposta e algumas considerações
}

\section{The song "O mundo é um moinho" as a pedagogical strategy for teaching transversal theme sexual orientation in school ... the proposal and some considerations}

\author{
${ }^{1}$ Marcelo Diniz Monteiro de Barros marcelodiniz@pucminas.br \\ 2 Priscilla Guimarães Zanella Diniz \\ 3 Tania Cremonini de Araújo-Jorge
}

\section{RESUMO}

De acordo com os Parâmetros Curriculares Nacionais, a linguagem musical pode ser utilizada por várias disciplinas com a finalidade de promover interesse e motivação no ensino. A literatura científica informa que pessoas cegas têm melhor desempenho em tarefas de processamento tátil e auditivo. Diversos trabalhos já foram desenvolvidos no campo tátil para alunos cegos. Entretanto, são escassos os materiais desenvolvidos no campo auditivo. Procurou-se destacar o potencial pedagógico da música "O mundo é um moinho" composta por Cartola, como estratégia de ensino do tema transversal “Orientação Sexual” na escola. A luz dos referenciais teóricos dos humanistas Carl Rogers e Paulo Freire foi preparada uma atividade apresentando a alunos cegos a letra desta música em Língua Portuguesa e na linguagem Braille. O prazer da escuta e o bom envolvimento dos alunos no debate que se seguiu confirmaram dados que temos produzido quanto a pertinência do uso desta estratégia.

Palavras-chave: ensino de ciências; música popular brasileira; estratégia pedagógica inclusiva.

\begin{abstract}
In accordance to the National Curriculum Parameters, the musical language can be used by various disciplines in order to promote interest and motivation in teaching. The scientific literature reports that blind people have better performance in tasks of tactile and auditory processing. Several studies have been developed in the tactile field to blind students. However, there are few materials developed in the auditory field. It was tried to highlight the pedagogical potential of music "O mundo é um moinho" composed by Cartola, as the transversal theme "Sexual Orientation" in school teaching strategy. In the light of the theoretical framework of humanist Carl Rogers and Paulo Freire it was prepared an activity to blind students presenting the lyrics of this song in Portuguese Language and Braille. The pleasure of good listening and student involvement in the debate that followed confirmed data we have produced as the pertinence of using this strategy.
\end{abstract}

Keywords: science education; brazilian popular music; inclusive pedagogical strategy.

\footnotetext{
1 Pontifícia Universidade Católica de Minas Gerais - Departamento de Ciências Biológicas. Instituto Oswaldo Cruz - Laboratório de Inovações em Terapias, Ensino e Bioprodutos.

2 Professora da Escola Estadual Prof. Caetano Azeredo - SEE-MG. Mestre em Ensino de Ciências pela Pontifícia Universidade Católica de Minas Gerais.

3 Pesquisador Titular em Saúde Pública do Instituto Oswaldo Cruz - Laboratório de Inovações em Terapias, Ensino e Bioprodutos - LITEB.
} 


\section{INTRODUÇÃO}

De acordo com os Parâmetros Curriculares Nacionais (1997) a linguagem musical pode ser utilizada no ensino, pelas mais variadas disciplinas, com a finalidade de promover interesse e motivação dos alunos.

A música faz parte do cotidiano humano, traduzindo sentimentos, situações, informações acerca das pessoas e demais seres vivos, dos processos científicos e dos espaços em que vivemos. Pode-se observar que o campo das formas musicais é verdadeiramente fértil e de fácil assimilação, portanto útil para o trabalho do professor que deseja renovar, dinamizar e buscar maior eficiência de aprendizado em seu modo de apresentar a matéria (FERREIRA, 2002).

A música e as letras que lhe agregam conteúdo podem ser uma importante alternativa para estreitar o diálogo entre alunos, professores e conhecimento científico, uma vez que abordam temáticas com grande potencial de problematização e que estão presentes de forma significativa na vida do aluno (BARROS et al. 2013). A música pode, ainda, fazer um segundo caminho que não o da aula expositiva, aumentando a sensibilidade e a criatividade para a construção de relações entre o conteúdo da música refletido na letra que a compõe e o conhecimento científico (SILVEIRA e KIOURANIS, 2008).

Pessoas cegas têm melhor desempenho em tarefas de processamento tátil e auditivo. Diversos trabalhos já foram desenvolvidos no campo tátil para alunos cegos, como os de Fernandes (2004), Andrezzo (2005) e Ferreira (2006). Entretanto, são mais escassos os materiais desenvolvidos no campo auditivo (NUNES e LOMÔNACO, 2010; MORAES, 2007).

Assim, com base na experiência prévia com oficinas dialógicas de músicas para alunos do ensino fundamental, com visão normal, procurou-se destacar o potencial pedagógico da música "O mundo é um moinho" (disco lançado em 1998), composta por Angenor de Oliveira, o popular Cartola, como estratégia de ensino do tema transversal Orientação Sexual na escola, destinada aos alunos das séries finais do Ensino Fundamental. Cartola foi um dos maiores nomes da música popular brasileira e apresentou, em 1974, em entrevista a Rádio Jornal do Brasil, o seu samba ainda inédito intitulado "O mundo é um moinho” (ALBIN, 2006).

\section{METODOLOGIA}

Foi preparada uma oficina dialógica de música com atividades baseadas na concepção humanista de aprendizagem (MOREIRA, 1985; MOREIRA, 2011a), à luz dos referenciais teóricos de Carl Rogers (2009) e Paulo Freire (2011), em Língua Portuguesa e na linguagem Braille, de forma a associar a letra da música "O mundo é um moinho” ao ensino de ciências, abordando o tema transversal orientação sexual de forma lúdica e inclusiva.

A oficina é composta de três momentos que consistem em: apresentação auditiva da música acompanhada da apresentação visual e tátil da letra para os alunos, elaboração de respostas às questões propostas e discussão das mesmas em forma de roda de conversa com os alunos. Sugere-se, inclusive, que o professor coloque a música mais de uma vez (uma apenas com audição, para o exercício de observação auditiva que mesmo pessoas videntes podem fazer com olhos fechados, e outra com audição e acompanhamento da leitura da letra em português ou em Braille) antes de passar para a segunda parte da atividade. O objetivo é que os alunos atentem para o conteúdo da música e reflitam sobre a letra, num contexto de prazer e ludicidade pela apreciação de uma melodia importante na música popular brasileira. 


\section{RESULTADOS: DINÂMICA DA OFICINA DIALÓGICA PROPOSTA}

1. Apresentação da atividade proposta pelo professor/mediador: "Nessa atividade vamos ouvir e observar, de forma bem atenta, a letra da música apresentada a seguir”:

\section{O mundo é um moinho.}

Composição: Cartola

Ainda é cedo, amor

Mal começastes a conhecer a vida

Já anuncias a hora de partida

Sem saber mesmo o rumo que irás tomar

Preste atenção, querida

Embora eu saiba que estás resolvida

Em cada esquina cai um pouco a tua vida

Em pouco tempo não serás mais o que és

Ouça-me bem, amor

Preste atenção, o mundo é um moinho

Vai triturar teus sonhos, tão mesquinho

Vai reduzir as ilusões a pó

Preste atenção, querida

De cada amor tu herdarás só o cinismo

Quando notares estás à beira do abismo

Abismo que cavaste com os teus pés

2. Debate entre o professor/mediador e os discentes: depois da escuta atenta da canção, a palavra era dada aos alunos, que se inscreviam interessados e motivados em participar das discussões acerca da letra da música.

3. Proposta de questões que devem ser respondidadas pelos alunos: após a escuta cuidadosa da música e de uma análise detalhada da sua letra, em conjunto com o professor e os colegas de sala, propomos que sejam respondidas as seguintes perguntas:

a. O termo “... mal começaste a conhecer a vida...” pode permitir a interpretação de que o adolescente ainda não tem condições de exercer determinadas atitudes e comportamentos? Como se pode caracterizar esse conhecimento nos aspectos biológico, afetivo, psicológico e social?

b. Freqüentemente encontramos alguns jovens menosprezando pessoas mais velhas, sem respeito, educação e atitudes de cooperação. Você poderia associar o termo "em pouco tempo não serás mais o que és” com a finitude humana e o envelhecimento, produzindo um texto?

c. Que tal escrever alguns sonhos de adolescentes que são “reduzidos a pó”? Você pode registrá-los e, posteriormente, escrever também sobre quais foram os motivos que favoreceram essa transformação?

d. Quais seriam pelo menos três comportamentos ou condutas que podem fazer com que os adolescentes “cavem o próprio abismo"? 
e. Em sua opinião o que o autor está querendo dizer através da música? Justifique detalhadamente a sua resposta.

f. Usando a mesma música, você poderia imaginar uma paródia para tratar de algum outro assunto de modo a sensibilizar quem a escuta?

g. Você seria capaz de indicar outras músicas que possam ser trabalhadas dentro do tema transversal Orientação sexual?

h. Agora é a sua vez: que tal bolar uma pergunta que a música lhe inspire e a seguir respondê-la?

\section{CONSIDERAÇÕES FINAIS}

Espera-se, ao final da oficina, e com a mediação do conhecimento efetuada pelo professor, que o adolescente reconheça a sua condição de pessoa em desenvolvimento e evite, ao máximo, atitudes arrogantes, comportamentos inadequados e que o coloquem em situações de vulnerabilidade, desenvolvendo, sempre que possível, atos de cooperação e auxílio ao próximo. A atividade procura trabalhar os conceitos sem prescrição ou autoritarismo, de modo a que os alunos possam refletir consigo mesmo e em conjunto com os colegas sobre o tema transversal "Orientação Sexual” associado ao ensino e a importância do mesmo em suas vidas. A presente atividade sugere a construção do conhecimento e a promoção de valores desejáveis a partir do reconhecimento da cultura brasileira e possibilita uma forma de aprender que inclui alunos com necessidades educacionais especiais visuais e que precisa ser mais estimulada pelas escolas do nosso país. 


\section{REFERÊNCIAS}

ALBIN, R.C. Dicionário Houaiss Ilustrado: Música Popular Brasileira. Rio de Janeiro: Paracatu, 1155 p., 2006.

ANDREZZO, K.L. Um estudo do uso de padrões figurativos na aprendizagem de Álgebra por alunos sem acuidade visual. Dissertação de Mestrado. São Paulo: Pontifícia Universidade Católica de São Paulo, 2005.

BARROS, M.D.M.; ZANELLA, P.G.; ARAÚJO-JORGE, T.C. A música pode ser uma estratégia para o ensino de ciências naturais? Analisando concepções de professores da educação básica. Revista Ensaio, v.15, n. 1, p. 81-94, 2013.

BRASIL. Secretaria de Educação Fundamental. Parâmetros curriculares nacionais: terceiro e quarto ciclos do ensino fundamental: orientação sexual. Brasília: MEC/SEF, 1997.

CARTOLA. O mundo é um moinho. In: CARTOLA. O mundo é um moinho. Rio de Janeiro: EMI, 1998. Faixa 1. 1 CD.

FERNANDES, S.H.A.A. Uma análise vygotskiana da apropriação do conceito de simetria por aprendizes sem acuidade visual. Dissertação de Mestrado. São Paulo: Pontifícia Universidade Católica de São Paulo, 2004.

FERREIRA, G.L. O design colaborativo de uma ferramenta para representação de gráficos por aprendizes sem acuidade visual. Dissertação de Mestrado. São Paulo: Pontifícia Universidade Católica de São Paulo, 2006.

FERREIRA, M. Como usar a música na sala de aula. - 2. ed. - São Paulo: Contexto, 2002.

FREIRE, P. Pedagogia da autonomia: saberes necessários à prática educativa. 43ª ed. São Paulo: Paz e Terra, 2011.

MORAES, M. Modos de intervir com jovens deficientes visuais: dois estudos de caso. Revista Semestral da Associação Brasileira de Psicologia Escolar e Educacional (ABRAPEE), v.11, n. 2, p. 311-322, 2007.

MOREIRA, M.A. Ensino e aprendizagem: enfoques teóricos. 2a ed. São Paulo: Moraes, 1985.

MOREIRA, M. A. Teorias de aprendizagem. $2^{\mathrm{a}}$ ed. São Paulo: EPU, 2011a.

NUNES, S.; LOMÔNACO, J.F.B. O aluno cego: preconceitos e potencialidades. Revista Semestral da Associação Brasileira de Psicologia Escolar e Educacional (ABRAPEE), v.14, n. 1, p. 55-64, 2010.

ROGERS, C.R. Tornar-se pessoa. $6^{a}$ ed. São Paulo: Martins Fontes, 2009.

SILVEIRA, M.P.; KIOURANIS, N.M.M. A música e o ensino de química. Química nova na escola. São Paulo, n.28, p.28-31, 2008. 